\title{
PENGEMBANGAN MODUL ILMU PENGETAHUAN ALAM BERBASIS ETNOSAINS PADA MATERI EKOSISTEM UNTUK MENINGKATKAN JIWA KONSERVASI SISWA SMP KELAS VII
}

\author{
Daista Gusmarti ${ }^{1}$, Andang Sunarto ${ }^{2}$, Ahmad Walid $^{3}$ \\ ${ }^{1,2,3}$ Universitas Islam Negeri Fatmawati Soekarno Bengkulu
}

\section{INFO ARTIKEL}

Diterima: $12-7-2021$

Disetujui: 3-9-2021

\begin{abstract}
Abstrak: Penelitian ini bertujuan untuk mengetahui pengembangan modul IPA berbasis etnosains pada materi ekosistem. kedua, mengetahui kelayakan dan efektifitas modul IPA berbasis etnosains pada materi ekosistem.Jenis penelitian yang digunakan dalam penelitian ini adalah $\mathrm{R} \& \mathrm{D} /$ Research and Development dengan pendekatan kuantitatif. hasil penelitian disimpulkan bahwa pertama, pengembangan modul pembelajaran IPA berbasis etnosains materi ekosistem menggunakan metode pengembangan Borg \& Gall yang terdiri dari enam langkah. Kedua, kelayakan modul diuji oleh 3 orang dosen yaitu: 1 dosen sebagai ahli bahasa, 1 dosen sebagai ahli materi, dan 1 dosen ahli media/desain. Berdasarkan hasil validasi bahasa $90 \%$, validasi materi $865 \%$, dan validasi media/desain $90 \%$. Modul pembelajaran IPA berbasis etnosains materi ekosistem termasuk dalam kriteria sangat layak digunakan tanpa direvisi.
\end{abstract}

Kata Kunci:
Pengembangan, Modul
IPA, Etnosains, Jiwa
Konservasi

\begin{abstract}
This study aims to determine the development of ethnosciencebased science modules on ecosystem materials. Second, knowing the feasibility and effectiveness of ethnoscience-based science modules on ecosystem materials. The type of research used in this research is $R \& D /$ Research and Development with a quantitative approach. The results of the study concluded that first, the development of an ethnoscience learning module based on ecosystem material using the Borg \& Gall development method which consists of six steps. Second, the feasibility of the module was tested by 3 lecturers, namely: 1 lecturer as a linguist, 1 lecturer as a material expert, and 1 lecturer as a media/design expert. Based on the results of 90\% language validation, $865 \%$ material validation, and $90 \%$ media/design validation. The ethnoscience-based science learning module for ecosystem materials is included in the criteria for being very suitable for use without being revised.
\end{abstract}

$\begin{array}{ll}\text { Nama } & : \text { Daista Gusmarti }{ }^{1} \text { Andang Sunarto }{ }^{2}, \text { Ahmad Walid }^{3} \\ \text { Institusi } & : \text { Universitas Islam Negeri Fatmawati Soekarno Bengkulu } \\ \text { Surel } & \begin{array}{l}\text { daistagusmarty@gmail.com } \\ \text { ahmadwalid angang99@ amainbengkulu.ac..jom }\end{array}\end{array}$

Proses belajar mengajar adalah terjadinya interaksi antara guru dan murid dalam suatu pembelajaran untuk mencapai suatu tujuan yang di inginkan yaitu tujuan pendidikan. Tujuan pendidikan tidak akan tercapai dengan baik apabila proses interaksi belajar mengajar tidak pernah berlansung dalam pendidikan. Undang-undang Republik Indonesia Nomor 20 Tahun 2003 Sistem Pendidikan Nasional pasal 1 ayat 1 menyebutkan bahwa: Pendidikan adalah usaha sadar dan terencana untuk mewujudkan suasana belajar dan proses pembelajaran agar peserta didik secara aktif mengembangkan potensi dirinya untuk memiliki kekuatan spiritual keagamaan, pengendalian diri, kepribadian, kecerdasan, akhlak mulia, serta keterampilan yang diperlukan dirinya, masyarakat, bangsa dan negara. Masalah pendidikan yang dihadapi dewasa ini yang sangat urgen adalah rendahnya mutu pendidikan pada setiap jenjang pendidikan, khususnya pada pendidikan dasar dan menengah. Berbagai usaha telah dilakukan untuk meningkatkan mutu pendidikan antara lain melalui berbagai pelatihan dan peningkatan kualitas guru, penyediaan dan perbaikan sarana prasarana pendidikan serta perbaikan kurikulum dan peningkatan mutu menajemen pendidikan sekolah (Maesaroh, 2013). 
KARANGAN: Jurnal Kependidikan, Pembelajaran, dan Pengembangan, Vol 03, No 02, Bulan September, Tahun 2021, Hal 97-101

Guru yang sering disebut pendidik diwajibkan memiliki peran untuk mendorong siswa secara aktif dalam mengembangkan pontensi yang dimiliki peserta didik dan mampu menjadi model dalam pembelajaran atau tauladan (leaner model) (Halim, 2019). Guru juga harus mengikuti perkembanagan arus pendidikan akhir yang sebenarnya guru dan murid mampu belajar bersama" (Suryadi, 2012).

Tantangan di era pengetahuan yang semakin dinamis, berkembang dan semakin maju diperlukan sumber daya manusia yang memiliki keterampilan intelektual tingkat tinggi yang melibatkan kemampuan penalaran yang logis, sistematis, kritis, cermat, dan kreatif serta memiliki kompetisi sikap yang baik dalam mengkomunikasikan gagasan atau memecahkan masalah. Kemampuan-kemampuan tersebut dapat dikembangkan melalui pendidikan yang pada dasarnya merupakan suatu proses membantu manusia dalam mengembangkan dirinya sehingga mampu menghadapi segala perubahan dan permasalahan dalam era globalisasi (Asiyah \& Walid, 2018).

Ilmu Pengetahuan Alam (IPA) yang merupakan hasil kegiatan manusia berupa pengetahuan, gagasan dan konsep yang terorganisasi tentang alam sekitar yang diperoleh dari pengalaman melalui serangkaian proses ilmiah. Proses itu antara lain penyelidikan, penyusunan dan pengujian gagasan. Selain itu mata pelajaran IPA adalah program untuk menanamkan dan mengembangkan keterampilan, sikap dan nilai ilmiah pada diri siswa serta mencintai dan menghargai kekuasan Tuhan Yang Maha Esa (Trianto, 2010).

Adapun menurut Taksonomi Bloom sebagaimana dikutip oleh Trianto bahwa tujuan pendidikan IPA diharapkan bukan hanya memberikan pengetahuan (kognitif) tetapi juga memberikan keterampilan (psikomotorik), kemampuan sikap ilmiah (afektif), pemahaman, kebiasaan dan apresiasi di dalam mencari jawaban terhadap suatu permasalahan. Hal tersebut menuntut agar guru sebagai pengelola pembelajaran dapat menyediakan lingkungan belajar yang kondusif, pendekatan pembelajaran yang sesuai dan dapat melibatkan siswa secara aktif dalam pembelajaran, sehingga siswa bukan hanya menerima pengetahuan dari apa yang ia dengar tetapi juga dari apa yang la lihat, dan apa yang ia lakukan serta mampu IPA khususnya akan memberikan kesempatan bagi siswa untuk memahami konsep IPA melalui lingkungan yang ada di sekitarnya (Trianto, 2010). Ilmu Pengetahuan Alam melibatkan berbagai aspek yang saling berkaitan. Karena itu, untuk mencipkakan pembelajaran yang menjadikan siswa aktif maka diperlukan berbagai keahlian khusus seorang guru diantaranya adalah ketrampilan guru dalam mengajar (Putra et al., 2015).

Selain mengajar dan mendidik tugas lain yang harus dilakukan pendidik ialah dapat mengelola kelas dengan efektif demi kenyamanan dan ketenangan dalam proses belajar mengajar. Tindakan pengelolaan kelas adalah tindakan yang dilakukan oleh pendidik dalam rangka penyediaan kondisi yang optimal agar proses belajar mengajar berlangsung efektif. Jadi dapat di simpulkan bahwa tindakan pengelolaan kelas merupakan salah satu pendukung dalam melancarkan proses pembelajaran agar kegiatan belajar mengajar berlangsung efektif (Adi et al., 2018). Pembelajaran seperti ini membuat siswa pasif karena siswa berada pada rutinitas yang membosankan sehingga pembelajaran kurang menarik. Pada umumnya pembelajaran lebih banyak memaparkan, fakta, pengetahuan, hukum, kemudian bisa dihapalkan bukan berlatih berfikir memecahkan masalah dan mengaitkannya dengan pengalaman emperis dalam kehidupan nyata sehingga pembelajara menjadi kurang bermakna.

Proses pembelajaran hendaknya menggunakan bahan pembelajaran atau bahan pendukung dalam penyampaian materi, bahan ajar salah satunya terdapat dalam bentuk cetak yaitu modul. Penggunaan bahan ajar modul akan sangat membantu pendidik ketika menyampaikan materi biologi kepada peserta didik dimana materi dalam modul dapat dimuat dengan disesuaikan kebutuhan peserta didik dan peserta didik dapat belajar secara mandiri.

Etnosains merupakan salah satu terobosan baru dengan kurikulum dan karakteristik siswa. Kata ethnoscience (etnosains) berasal dari kata ethno (bahasaa Yunani) yang berarti bangsa, dan scientia (bahasa Lain) artinya pengetahuan. Etnosains merupakan pengetahuan yang dimiliki oleh suatu komunitas budaya, kemudian ilmu ini mempelajari atau mengkaji system pengetahuan dan tipe-tipe kognitif budaya tertentu. Penekanan pada pengetahuan asli dan khas dari suatu komunitas budaya. Etnosains merupakan suatu kajian dari budaya 
KARANGAN: Jurnal Kependidikan, Pembelajaran, dan Pengembangan, Vol 03, No 02, Bulan September, Tahun 2021, Hal 97-101

masyarakat dan fenomena yang berhubungan dengan alam yang terdapat di dalam masyarakat. Etnosains bersifat turun temurun dan merupakan pengetahuan-pengetahuan asli masyarakat (Tandililing, 2014). Etnosains adalah cabang pengkajian budaya yang berusaha memahami bagaimana pribumi memahami alam mereka. Pribumi biasanya memiliki ideology dan falsafah hidup yang mempengaruhi mereka salah satu bentuk etnografi baru (the new ethnography) (Tandililing, 2014).

\section{METODE PENELITIAN}

Jenis penelitian yang digunakan dalam penelitian ini adalah $\mathrm{R} \& \mathrm{D} /$ Research and Development dengan pendekatan kuantitatif. Metode penelitian dan pengembangan atau dalam bahasa Inggrisnya Research and Development adalah metode penelitian yang digunakan untuk menghasilkan produk tertentu, dan menguji keefektifan produk tersebut (Sudjana, 2005). Pengertian penelitian pengembangan menurut Borg and Gall "research and development is a powerful strategy for improving practice. It is a process used to develop and validate educational products".

Pengertian tersebut dapat dijelaskan bahwa "penenelitian dan pengembangan merupakan strategi yang kuat untuk meningkatkan praktek. Itu adalah proses yang digunakan untuk mengembangkan dan memvalidasi produk pendidikan". Produk pendidikan yang dimaksud dalam penelitian dan pengembangan mengandung empat pengertian pokok. Pertama, produk tersebut tidak hanya meliputi perangkat keras, seperti modul, buku teks, video dan film pembelajaran atau perangkat keras yang sejenisnya, tetapi juga perangkat lunak seperti kurikulum, evaluasi, model pembelajaran, prosedur dan proses pembelajaran, dan lain-lain. Kedua, produk tersebut dapat berarti produk baru atau memodifikasi produk yang sudah ada. Ketiga, produk yang dikembangkan merupakan produk yang betul-betul bermanfaat bagi dunia pendidikan. Keempat, produk tersebut dapat dipertanggungjawabkan, baik secara praktis maupun keilmuan (Arifin, 2012).

\section{HASIL DAN PEMBAHASAN}

\section{Hasil Analisis Kebutuhan Modul IPA Berbasis Etnosains pada Materi Ekosistem}

Kegiatan penelitian pengembangan pada tahap 1 yaitu analisis kebutuhan terhadap modul IPA berbasis etnosains pada materi ekosistem. Analisis kebutuhan dilakukan untuk mengumpulkan informasi tentang kebutuhan belajar siswa dan karakteristik modul IPA berbasis etnosains pada materi ekosistem yang dibutuhkan sebagai sumber belajar alternatif.

Analisis kebutuhan tersebut dilakukan dengan menggunakan angket yang melibatkan guru IPA di SMP Negeri 11 Kecamatan Pondok Suguh Kabuapaten Mukomuko. Analisis kebutuhan juga melibatkan beberapa siswa kelas VII SMP Negeri 11 Kecamatan Pondok Suguh Kabuapaten Mukomuko. Hasil analisis kebutuhan berdasarkan angket yang diberikan kepada guru mata pelajaran IPA dapat dilihat pada tabel berikut:

Tabel 1. Analisis Kebutuhan Guru

\begin{tabular}{|l|l|l|}
\hline No & Aspek yang Ingin Diketahui & Hasil Analisis Kebutuhan Guru \\
\hline 1 & $\begin{array}{l}\text { Penggunaan sumber belajar } \\
\text { materi ekosistem }\end{array}$ & $\begin{array}{l}\text { Sebagian besar responden tidak memiliki buku pegangan } \\
\text { lain untuk membelajarkan materi ekosistem. Selain itu }\end{array}$ \\
& & semua responden guru menyatakan buku teks pelajaran \\
& yang dimiliki banyak kekurangan, yaitu format yang \\
& kurang menarik, penyajian materi terlalu instan sehingga \\
& memperlemah kreativitas siswa dan membuat siswa \\
& merasa bosan belajar. Semua responden guru \\
& menyatakan tidak menggunakan alternatif modul untuk \\
& menanggulangi permasalahan tersebut \\
\hline
\end{tabular}


KARANGAN: Jurnal Kependidikan, Pembelajaran, dan Pengembangan, Vol 03, No 02, Bulan September, Tahun 2021, Hal 97-101

\begin{tabular}{|l|l|l|}
\hline No & Aspek yang Ingin Diketahui & Hasil Analisis Kebutuhan Guru \\
\hline 2 & $\begin{array}{l}\text { Pelaksanaan kegiatan } \\
\text { pembelajaran materi ekosistem }\end{array}$ & $\begin{array}{l}\text { Dari tiga orang guru hanya satu responden guru yang } \\
\text { menyatakan pernah mengajarkan materi ekosistem } \\
\text { melibatkan etnosains, selebihnya hanya menggunakan } \\
\text { metode ceramah saja }\end{array}$ \\
\hline 3 & $\begin{array}{l}\text { Keterbatasan dan kesulitan yang } \\
\text { dirasakan guru dalam } \\
\text { pembelajaran materi ekosistem }\end{array}$ & $\begin{array}{l}\text { Materi ekosistem kebanyakan mengandung konsep dan } \\
\text { praktikum, namun jarang ditemukan buku/modul yang } \\
\text { dapat memberikan penjelasan/ilustrasi konsep dengan } \\
\text { baik }\end{array}$ \\
\hline 4 & Kebutuhan akan modul & $\begin{array}{l}\text { Responden membutuhkan modul yang menarik agar } \\
\text { siswa merasa tertarik dan senang mempelajari IPA. } \\
\text { Modul tersebut berisi nilai-nilai etnosains yang dapat } \\
\text { membantu siswa lebih mudah memahami konsep IPA } \\
\text { dan membantu untuk meningkatkan jiwa konservasi } \\
\text { siswa }\end{array}$ \\
\hline
\end{tabular}

Berdasarkan hasil analisis kebutuhan terhadap guru, tersebut diketahui bahwa guru mengalami kendala dalam mengajarkan materi ekosistem kepada siswa sehingga siswa tidak memiliki antusias mengikuti pembelajaran IPA, hal ini salah-satunya disebabkan oleh keterbatasan buku teks yang dimiliki siswa. Hasil analisis kebutuhan siswa terhadap modul pembelajaran IPA berbasis etnosains

\section{Desain Produk}

Setelah melakukan analisis kebutuhan dan mengetahui permasalahan yang ada di lapangan, maka langkah selanjutnya adalah mengembangkan produk awal modul pembelajaran IPA berbasis etnosains materi ekosistem yang dapat menjawab permasalahan tersebut. Tahapan dalam mengembangkan produk awal ini yaitu penyusunan Garis Besar Isi Modul (GBIM).

\section{Hasil Validasi Produk Awal}

Tahap validasi/penilaian kelayakan draf 1 modul pembelajaran IPA berbasis etosains materi ekosistem dilakukan dengan melibatkan 3 dosen para ahli yaitu ahli bahasa, ahli materi, dan ahli media/desain, dan 1 orang guru IPA. Validasi dilakukan untuk memberikan penilaian kelayakan modul pembelajaran IPA berbasis etosains materi ekosistem yang dikembangkan meliputi kelayakan materi/isi, kelayakan bahasa, dan kelayakan desain/media.

\section{Pembahasan Hasil Perencanaan}

Tahapan pendefinisian dilakukan dengan melakukan observasi di sekolah terhadap sumber daya sekolah, sumber belajar siswa, menyebarkan angket kepada siswa dan guru IPA. Hasil observasi bahwa sumber belajar yang digunakan berupa buku paket dari kemendikbud dan LKS, belum ada modul, pembelajaran masih didominasi ceramah, diskusi.

Berdasarkan hasil analisis kebutuhan guru, dapat diketahui bahwa guru kesulitan mendapatkan bahan ajar yang dapat menarik antusias siswa untuk mempelajari IPAmateri ekosistem. Sejalan dengan itu, berdasarkan hasil analisis kebutuhan siswa, dapat diketahui bahwa beberapa siswa memiliki buku teks sebagai pegangan, namun mereka merasa kesulitan mempelajari buku tersebut karena penyajiannya yang monoton dan verbalistik.

Pemilihan model dan metode pembelajaran yang baik perlu dipilih agar siswa merasa termotivasi dan antusias mempelajari IPA, model dan metode pembelajaran yang dapat melibatkan siswa secara langsung untuk menemukan konsep dari suatu materi. Minimnya pengaitan ilmu IPA yang dipelajari siswa dengan aplikasi dalam kehidupan sehari-hari mengurangi kebermanfaatan mempelajari IPA khususnya materi ekosistem. Oleh karena itu diharapkan pengembangan sebuah modul yang menyajikan suatu materi IPA materi ekosistem yang menyenangkan dan meningkatkan antusias siswa untuk mempelajarinya. Modul yang dikembangkan juga diharapkan dapat meminimalisir verbalistis seperti pada buku teks dengan memberikan ilustrasi-ilustrasi yang baik dan mampu mengaitkan materi dengan aplikasi dalam kehidupan sehari-hari siswa dan nilai-nilai etnosains yang ada.

\section{KESIMPULAN}


KARANGAN: Jurnal Kependidikan, Pembelajaran, dan Pengembangan, Vol 03, No 02, Bulan September, Tahun 2021, Hal 97-101

1. Pengembangan modul pembelajaran IPA berbasis etnosains materi ekosistem menggunakan metode pengembangan Borg \& Gall yang terdiri dari enam langkah.

2. Kelayakan modul diuji oleh 3 orang dosen yaitu: 1 dosen sebagai ahli bahasa, 1 dosen sebagai ahli materi, dan 1 dosen ahli media/desain. Berdasarkan hasil validasi bahasa 90\%, validasi materi $865 \%$, dan validasi media/desain 90\%. Modul pembelajaran IPA berbasis etnosains materi ekosistem termasuk dalam kriteria sangat layak digunakan tanpa direvisi.

3. Kepraktisan modul pembelajran berdasarkan hasil respon siswa yang dilakukan pada uji coba lapangan terbatas/uji coba skala kecil menunjukkan bahwa modul pembelajaran IPA berbasis etnosains materi ekosistem termasuk dalam kriteria sangat menarik/sangat baik untuk digunakan tanpa direvisi.

\section{DAFTAR RUJUKAN}

Adi, S. S., Kusumawardani, I. N., \& Fransisca, J. V. (2018). Peran Guru Dalam Mengelola Kelas Yang Digambarkan Dalam Film Beyond The Blackboard Karya Jeff Bleckner. Edcomtech Jurnal Kajian Teknologi Pendidikan, 3(2), 113-126.

Arifin, Z. (2012). Model penelitian dan pengembangan. PT Remaja Rosdakarya, Bandung.

Asiyah, A., \& Walid, A. (2018). Pengembangan Modul Berbasis Challenge Based Learning Materi Lingkungan untuk Memberdayakan Kemampuan Interpretasi dan Sikap Peduli Lingkungan Siswa. At-Ta'lim: Media Informasi Pendidikan Islam, 16(2), 275-288.

Halim, M. L. Al. (2019). INCREASING ENGLISH ACHIEVEMENT THROUGH TWO STAY- TWO STRAY ( TS-TS ) METHOD. KARANGAN: Jurnal Kependidikan, Pembelajaran, Dan Pengembangan, 01(02), 102-109.

Maesaroh, S. (2013). Peranan metode pembelajaran terhadap minat dan prestasi belajar pendidikan agama Islam. Jurnal Kependidikan, 1(1), 150-168.

Putra, N. A. R., Abdurrahman, A., \& Suana, W. (2015). Pengaruh Keterampilan Proses Sains dan Sikap Ilmiah terhadap Pemahaman Konsep IPA Siswa SMP. Jurnal Pembelajaran Fisika, 3(4).

Sudjana, N. (2005). Metode Penelitian Pendidikan Pendekatan Kuantitatif-Kualitatif dan R\&D. Bandung: PT Remaja Rosdakarya.

Suryadi, A. (2012). Pendidikan, Investasi SDM dan Pembangunan: Isu. Teori dan Aplikasi Untuk Pembangunan Pendidikan dan Sumber Daya Manusia Indonesia. Bandung: Widya Aksara Pres.

Tandililing, E. (2014). Pengembangan Etnosains dalam pembelajaran pendidikan sains di sekolah. Diambil Kembali Dari Prodi Pendidikan Fisika UNTAN: Http://Fkip. Untan. Ac. Id/Prodi/Fisika/Pengembangan-Etnosains-Dalam-Pembelajaran-Pendidikan-Sains-DiSekolah. Html.

Trianto, M. P. (2010). Model pembelajaran terpadu: Konsep, strategi, dan implementasinya dalam Kurikulum Tingkat Satuan Pendidikan (KTSP). Kuala Lumpur: Kemetrian Pengajaran Malaysia. 